\title{
Evolution of Percutaneous Endoscopic Lumbar Decompression
}

\author{
Yong Ahn \\ Department of Neurosurgery, Gil Medical Center, Gachon University College of Medicine, Incheon, Korea
}

Corresponding Author:

Yong Ahn, MD, PhD

Department of Neurosurgery, Gil Medical Center, Gachon University College of Medicine, 21, Namdong-daero 774 beon-gil, Namdong-gu, Incheon 21565, Korea

Tel: +82-32-460-3304

Fax: +82-32-460-3899

E-mail: ns-ay@hanmail.net

Received: May 7, 2019

Revised: May 28, 2019

Accepted: June 3, 2019

\begin{abstract}
Since Kambin and Hijikata firstly introduced the concept of percutaneous posterolateral lumbar discectomy, the technical improvement of percutaneous endoscopic lumbar discectomy (PELD) has been splendid in surgical approaches, design of optics and surgical instruments. The basic concept of the percutaneous endoscopic surgery has been evolved from an indirect intradiscal decompression to a direct epidural or foraminal neural decompression. Until now, the main topic of the percutaneous endoscopic surgery is soft disc herniation. However, the indications are broadening to the degenerative lumbar stenosis. Percutaneous endoscopic decompression technique using by endoscopic burr and punches will be effective and practical for various lumbar stenosis shortly.
\end{abstract}

Key Words: Decompression, Disc herniation, Lumbar, Percutaneous endoscopic, Stenosis

\section{INTRODUCTION}

In the field of minimally invasive spine surgery (MISS), preservation of normal tissues has become a major issue. The introduction of spinal endoscope and percutaneous technologies has been an encouraging sign of achieving splendid development of spinal minimalism. With recent advance and experience, nowadays, several advantages such as reducing blood loss, operation time, recovery period and terms to return to work have made percutaneous endoscopic spinal surgery to be differentiated from conventional open surgery. However, conventional surgeries have been still reported to be associated with good results and those have been accepted as a 'golden standard' until now. In such a situation, what the spine surgeons should look into is the ongoing evolution of surgical techniques as well as instruments toward 'minimization' of invasiveness. These days, the spectrum of minimally invasive spinal surgery with percutaneous endoscope is expanded from simple disc surgeries to decompression for spinal stenosis or even fusion surgery, of which percutaneous endoscopic disc surgery has been getting the worldwide attention.

\section{Percutaneous Discectomy}

The concept of posterolateral percutaneous discectomy was firstly introduced in 1973. Parvis Kambin conducted percutaneous indirect spinal canal decompression by nucleotomy using
Craig's cannula in a nonvisualized posterolateral approach ${ }^{1)}$. Hijikata firstly published the technique of nonvisualized posterolateral percutaneous discectomy in 1975, which was a standalone procedure ${ }^{2}$. In the mid-1980s, Onik introduced a motorized aspiration shaver to the percutaneous discectomy technique ${ }^{3)}$ and then, Onik and Maroon reported the clinical outcome of 'automated percutaneous discectomy' using the nucleotome ${ }^{4,5)}$.

\section{Percutaneous Endoscopic Discectomy for Contained Disc Herniation}

After the percutaneous discectomy age, an endoscope called "discoscope" was applied to the percutaneous discectomy technique for direct visualization. Hausmann and Forst ${ }^{6)}$ introduced a nucleoscope for viewing the intervertebral disc space. In 1990, Kambin also described an important illustration in the transforaminal approach, so called 'triangular working zone' in which there are neither vessel nor nerve ${ }^{1)}$. The safe zone is bordered anteriorly by the exiting nerve root, inferiorly by the end plate of the lower vertebra, posteriorly by the superior articular process of the inferior vertebra, and medially by the traversing nerve root. The definitive description of the triangular working zone enabled the introduction of larger endoscope with larger instruments and more sophisticated decompression without exiting nerve root damage. Mayer and Brock described the technique of percutaneous endoscopic lumbar discectomy (PELD) for contained disc herniation using an angled lens scope allowing dorsal 
vision around the annular tear ${ }^{7)}$. This was similar to Schreiber's biportal approach. They removed the herniated nucleus with rigid or flexible forceps, as well as with automated shaver system under intermittent endoscopic control (discoscopy). Since then, so called 'PELD' is one of the representative terms of endoscopic lumbar discectomy techniques.

\section{Percutaneous Endoscopic Discectomy for Non-contained Disc Herniation}

Mathews $1996^{8)}$ and Ditsworth 19989) opened the era of real transforaminal approach. Ditsworth described the technique in which a working channel endoscopy passes completely through the foramen into the spinal canal and the surgeon directly removes free fragments and decompresses the nerve root and dural $\mathrm{sac}^{9}$. Since then, a truly transforaminal approach, as opposed to just going through part of the foramen and into the disc, has been developed and the target disc pathology is broaden from contained disc herniation to non-contained disc herniation.

The basic concept of the percutaneous endoscopic surgery has been evolved from an indirect intradiscal decompression to a direct epidural or selective neural decompression. The working space has been extended from central nucleus to peri-annular and finally, epidural space ${ }^{10)}$. In the new millennium, various advanced endoscopic techniques have been developed. Selective endoscopic discectomy was named by Kambin ${ }^{11)}$ and Yeung ${ }^{12)}$ independently. Yeung et al. used the Yeung Endoscopic Spine System (YESS ${ }^{\mathrm{TM}}$ ) which has a rigid rod-lens, integrated, multichannel, wide-angled endoscope ${ }^{13)}$. They described the selective endoscopic discectomy technique for extruded lumbar disc herniation. They also introduced a foraminoplastic approach at the L5-S1 level. In 2003, the endoscopic surgical system became more contemporary as launching YESS designed around the transforaminalendoscopic approach for intradiscal and epiduroscopic procedures. Yeung et al. also described the utility of provocative intraoperative discography, thermal discoplasty and annuloplasty, and annular resection for creation of an annular window to perform foraminoplasty using abrasive drills, burrs, and lasers ${ }^{14)}$. Some authors reported the endoscopic technique for various situations such as recurrent disc herniation, disc herniation at L5-S1 level, migrated disc herniation or upper lumbar disc herniation. Ahn and Lee described the endoscopic technique for recurrent disc herniation and upper lumbar disc herniation ${ }^{15,16)}$. Sometimes the standard posterolateral approach might be associated with problems in reaching the epidural space due to anatomical peculiarities. This problem of poor visualization of the epidural space was solved with an extreme lateral approach described by Reutten et al. ${ }^{17)}$. They pointed out that the usual transforaminal access is posterolateral and associated with problems in reaching the epidural space directly with unhindered vision, and then they described an extreme lateral access into the spinal canal using the full-endoscopic uniportal transforaminal approach. At the same time, Schubert and Hoogland described a foraminoplastic approach with bone reamer to remove the migrated and sequestrated disc hernia- tion ${ }^{18)}$. They used a bone reamer to undercut the part of superior facet to reach the epidurally extruded disc fragment. Lee applied a classification system for the migrated disc herniation and demonstrated the clinical outcomes according to the disc migration zone ${ }^{19)}$.

\section{Percutaneous Endoscopic Foraminal Decompression}

Although various foraminoplastic approaches were introduced, most of the techniques were not for real foraminal decompression, but for approach to the intracanal pathologies. Therefore, the history of foraminal endoscopic decompression started in the late 1990s. Knight et al. introduced endoscopic laser foraminoplasty for various foraminal nerve root entrapment syndromes ${ }^{20)}$. The basic concept of foraminoplasty is reshaping foramen by ablating soft tissues such as foraminal ligaments and osteophyte using side-firing laser under endoscopic visualization. Ahn et al. described a percutaneous endoscopic lumbar foraminotomy technique using bone reamer and laser $^{21)}$. Schubert and Hoogland also reported the use of a bone reamer for foraminoplasty in case of migrated disc herniation ${ }^{18)}$. However, the previous techniques have limitations for definite foraminal decompression. The use of laser is effective for only neural entrapment caused by soft tissue or fragile osteophyte. However, it may be less effective for severe bony foraminal stenosis. Blind use of bone reamer also has inherent limitations such as bone bleeding and neural injury because it is a blind technique without any direct vision control. Nowadays, some authors reported more advanced endoscopic foraminal decompression techniques that can be performed for severe foraminal stenosis cases. The use of endoscopic burr and endo-punches enables a safer and more effective full-scale foraminal decompression ${ }^{10,22)}$.

\section{Percutaneous Endoscopic Lumbar Decompression for Lateral Recess Decompression}

The hypertrophy of the superior articular process is the most common cause of the lumbar lateral recess and foraminal stenosis. As a result, the traversing nerve root is opted to be compressed in the lateral recess zone. The transforaminal approach may be suitable for the treatment of the lateral recess stenosis. The approach angle is more efficient while preserving the facet joint with the transforaminal approach. The working sheath is usually engaged in the foramen, especially in the caudal surface of the superior articular process, not in the disc space ${ }^{18,21,23)}$. The tip of the superior articular process can be resected by a bone trephine or endoscopic burrs in an outside-to-inside manner. After bony resection, the thickened ligamentum flavum can be subsequently resected by endoscopic forceps and micropunches. Then the compressed traversing nerve root can be identified, and a sophisticated soft tissue decompression can be performed. An additional partial pediculectomy at the caudal part of the foramen may enhance the decompression effect. The essential technical point is the 
precise landing of the working sheath and sufficient decompression of the critical point, which is usually located around the hypertrophic superior articular process and ligamentum flavum. Technical obstacles against the complete decompression are the safe placement of the working sheath in the foramen, epidural bleeding, blurring of the endoscopic visual field, and confusion in the endoscopic anatomical discrimination. Thus, this technique is more challenging than the standard percutaneous endoscopic discectomy. However, an advanced and pracical techniques have been published with reliable outcomes ${ }^{24)}$.

\section{Percutaneous Endoscopic Lumbar Decompression for Central Stenosis}

For a definitive endoscopic decompression for central lumbar stenosis, the size of the working channel endoscope and the related instruments have become bigger and stronger.

The surgical technique can be performed using the standard method described in previous studies ${ }^{25,26)}$. The patient was placed in a prone position under general or epidural anesthesia. The initial landing point is the lateral edge of the interlaminar space. After serial dilation, the final working sheath was placed on the lamina. Then a percutaneous endoscopic laminotomy was performed from the medial border of the superior facet using the endoscopic burr and punches. Decompression under endoscopic control can be performed including cranial and caudal laminotomy, medial facetectomy, and removal of the ligamentum flavum. In the case of bilateral decompression, further decompression of the contralateral side is needed after ipsilateral decompression. The working channel endoscope and the working sheath were directed toward the contralateral side, dorsal to the dural sac. It is essential to leave the ligamentum flavum intact to protect the dural sac during the contralateral laminotomy. The bone resection over the ligamentum flavum should be conducted until the medial aspect of the contralateral facet can be reached. The remaining ligamentum flavum was then completely removed using the endoscopic punches and other supplementary instruments.

\section{SCIENTIFIC EVIDENCE}

A different kind of percutaneous endoscopic or full-endoscopic lumbar spine surgery technique has been emerging since Hijikata and Kambin developed the posterolateral percutaneous lumbar discectomy in the mid-1970s. The levels of evidence are variable according to the kind of each endoscopic surgery. Until now, only transforaminal endoscopic lumbar discectomy technique has been proven by some randomized trials $^{27-30)}$ and meta-analyses. According to the updated systematic reviews and meta-analysis, the therapeutic effects of the transforaminal endoscopic lumbar discectomy is not inferior to those of standard open lumbar microdiscectomy in terms of the success rate, complication rate, and recovery time ${ }^{31-33)}$. The secondly ranked endoscopic spine surgery technique is the interlaminar endoscopic lumbar discectomy and decompression.
Some published randomized trials and a few meta-analyses proved that this endoscopic technique is also not inferior to the standard open surgery ${ }^{25,26,34,35)}$. However, most studies demonstrating the effect of these techniques are still case series or technical notes. More high-quality randomized trials are required to confirm the clinical relevance and effectiveness of endoscopic decompression for lumbar stenosis.

\section{FUTURE PERSPECTIVE}

The technical improvement of percutaneous endoscopic lumbar surgery has been splendid in surgical approaches, design of optics and surgical instruments. Because of the rapid technical advancement, the paradigm of percutaneous endoscopic spine surgery is shifting. In earlier generations, the main topic of the percutaneous endoscopic surgery is soft disc herniation. Any stenotic component with lumbar disc herniation is regarded as a contraindication or a predictor of poor outcome for this technique. However, the indications are broadening to the degenerative lumbar stenosis. Percutaneous endoscopic decompression technique using by endoscopic burr and punches for various lumbar stenosis will be main issues of the next generation.

\section{REFERENCES}

1. Kambin P, Sampson S: Posterolateral percutaneous suction-excision of herniated lumbar intervertebral discs. Report of interim results. Clin Orthop Relat Res 207:37-43, 1986

2. Hijikata S: Percutaneous discectomy: a new treatment method for lumbar disc herniation. J Toden Hosp 5:5-13, 1975

3. Onik G, Helms CA, Ginsberg L, Hoaglund FT, Morris J: Percutaneous lumbar diskectomy using a new aspiration probe: porcine and cadaver model. Radiology 155:251-252, 1985

4. Maroon JC, Onik G: Percutaneous automated discectomy: a new method for lumbar disc removal. Technical note. J Neurosurg 66: 143-146, 1987

5. Onik G, Maroon J, Helms C, Schweigel J, Mooney V, Kahanovitz $\mathrm{N}$, et al: Automated percutaneous diskectomy: initial patient experience. Work in progress. Radiology 162:129-132, 1987

6. Hausmann B, Forst R. Nucleoscope: Instrumentarium for endoscopy of the intervertebral disc space. Arch Orthop Trauma Surg 102:57-59, 1983

7. Mayer HM, Brock M: Percutaneous endoscopic lumbar discectomy (PELD). Neurosurg Rev 16:115-120, 1993

8. Mathews HH: Transforaminal endoscopic microdiscectomy. Neurosurg Clin N Am 7:59-63, 1996

9. Ditsworth DA: Endoscopic transforaminal lumbar discectomy and reconfiguration: A postero-lateral approach into the spinal canal. Surg Neurol 49:588-597, 1998

10. Ahn Y: Transforaminal percutaneous endoscopic lumbar discectomy: technical tips to prevent complications. Expert Rev Med Devices 9:361-366, 2012

11. Kambin P, O'Brien E, Zhou L, Schaffer JL: Arthroscopic microdiscectomy and selective fragmentectomy. Clin Orthop Relat Res 347:150-167, 1998

12. Yeung AT, Tsou PM: Posterolateral endoscopic excision for 
lumbar disc herniation: Surgical technique, outcome, and complications in 307 consecutive cases. Spine (Phila Pa 1976) 27: 722-731, 2002

13. Yeung AT: Minimally invasive disc surgery with the yeung endoscopic spine system (YESS). Surg Technol Int 8:267-277, 1999

14. Yeung AT, Yeung CA: Advances in endoscopic disc and spine surgery: foraminal approach. Surg Technol Int 11:255-263, 2003

15. Ahn Y, Lee SH, Park WM, Lee HY, Shin SW, Kang HY: Percu taneous endoscopic lumbar discectomy for recurrent disc herniation: surgical technique, outcome, and prognostic factors of 43 consecutive cases. Spine (Phila Pa 1976) 29:E326, 2004

16. Ahn Y, Lee SH, Lee JH, Kim JU, Liu WC: Transforaminal percutaneous endoscopic lumbar discectomy for upper lumbar disc herniation: clinical outcome, prognostic factors, and technical consideration. Acta Neurochir (Wien) 151:199-206, 2009

17. Ruetten S, Komp M, Godolias G: An extreme lateral access for the surgery of lumbar disc herniations inside the spinal canal using the full-endoscopic uniportal transforaminal approach-technique and prospective results of 463 patients. Spine (Phila $\mathrm{Pa}$ 1976) 30:2570-2578, 2005

18. Schubert M, Hoogland T: Endoscopic transforaminal nucleotomy with foraminoplasty for lumbar disk herniation. Oper Orthop Traumatol 17:641-661, 2005

19. Lee S, Kim SK, Lee SH, Kim WJ, Choi WC, Choi G, et al: Percutaneous endoscopic lumbar discectomy for migrated disc herniation: classification of disc migration and surgical approaches. Eur Spine J 16:431-437, 2007

20. Knight MT, Vajda A, Jakab GV, Awan S: Endoscopic laser foraminoplasty on the lumbar spine--early experience. Minim Invasive Neurosurg 41:5-9, 1998

21. Ahn Y, Lee SH, Park WM, Lee HY: Posterolateral percutaneous endoscopic lumbar foraminotomy for L5-S1 foraminal or lateral exit zone stenosis. Technical note. J Neurosurg 99(3 Suppl):320323, 2003

22. Jasper GP, Francisco GM, Telfeian AE: A retrospective evaluation of the clinical success of transforaminal endoscopic discectomy with foraminotomy in geriatric patients. Pain Physician 16:225-229, 2013

23. Ahn Y: Percutaneous endoscopic decompression for lumbar spinal stenosis. Expert Rev Med Devices 11:605-616, 2014

24. Shin SH, Bae JS, Lee SH, Keum HJ, Kim HJ, Jang WS: Transforaminal endoscopic decompression for lumbar spinal stenosis: A novel surgical technique and clinical outcomes. World Neurosurg 114:e873-e882, 2018

25. Ruetten S, Komp M, Merk H, Godolias G: Surgical treatment for lumbar lateral recess stenosis with the full-endoscopic interlaminar approach versus conventional microsurgical technique: a prospective, randomized, controlled study. J Neurosurg Spine 10:476-485, 2009

26. Komp M, Hahn P, Oezdemir S, Giannakopoulos A, Heikenfeld $\mathrm{R}$, Kasch R, et al: Bilateral spinal decompression of lumbar central stenosis with the full-endoscopic interlaminar versus microsurgical laminotomy technique: a prospective, randomized, controlled study. Pain Physician 18:61-70, 2015

27. Mayer HM, Brock M: Percutaneous endoscopic discectomy: surgical technique and preliminary results compared to microsurgical discectomy. J Neurosurg 78:216-225, 1993

28. Hermantin FU, Peters T, Quartararo L, Kambin P: A prospective, randomized study comparing the results of open discectomy with those of video-assisted arthroscopic microdiscectomy. J Bone Joint Surg Am 81:958-965, 1999

29. Hoogland T, Schubert M, Miklitz B, Ramirez A: Transforaminal posterolateral endoscopic discectomy with or without the combination of a low-dose chymopapain: a prospective randomized study in 280 consecutive cases. Spine (Phila Pa 1976) 31:E890897, 2006

30. Ruetten S, Komp M, Merk H, Godolias G: Full-endoscopic interlaminar and transforaminal lumbar discectomy versus conventional microsurgical technique: A prospective, randomized, controlled study. Spine (Phila Pa 1976) 33:931-939, 2008

31. Cong L, Zhu Y, Tu G: A meta-analysis of endoscopic discectomy versus open discectomy for symptomatic lumbar disk herniation. Eur Spine J 25:134-143, 2016

32. Li XC, Zhong CF, Deng GB, Liang RW, Huang CM: Full-endoscopic procedures versus traditional discectomy surgery for discectomy: A systematic review and meta-analysis of current global clinical trials. Pain Physician 19:103-118, 2016

33. Ruan W, Feng F, Liu Z, Xie J, Cai L, Ping A: Comparison of percutaneous endoscopic lumbar discectomy versus open lumbar microdiscectomy for lumbar disc herniation: A meta-analysis. Int J Surg 31:86-92, 2016

34. Chen J, Jing X, Li C, Jiang Y, Cheng S, Ma J: Percutaneous endoscopic lumbar discectomy for L5S1 lumbar disc herniation using a transforaminal approach versus an interlaminar approach: A systematic review and meta-analysis. World Neurosurg 116:412-420.e2, 2018

35. Lee $\mathrm{CH}$, Choi M, Ryu DS, Choi I, Kim CH, Kim HS, et al: Efficacy and safety of full-endoscopic decompression via interlaminar approach for central or lateral recess spinal stenosis of the lumbar spine: A meta-analysis. Spine (Phila Pa 1976) 43: 1756-1764, 2018 